\title{
A HUMANIZAÇÃO DA CASA E DO INDIVÍDUO: PROJETO PAREDES- PINTURAS
}

Valéria da Silva Freitas

\begin{abstract}
Graduada em Administração de Empresas pela Universidade de São Paulo (2007), está finalizando o curso de Gestão de Projetos Culturais e Organização de Eventos pelo CELACC- ECA/USP. Desenvolve projetos sócio-culturais com organizações do terceiro setor. Pesquisa realizada sob orientação do Prof. Dr. Dennis de Oliveira.
\end{abstract}

\section{Resumo}

Inserido no contexto do cotidiano, a proposta deste estudo é compreender as novas percepções e os novos sentidos construídos pelos moradores ao verem suas casas pintadas, após a intervenção do Projeto PAREDES-PINTURAS. De caráter exploratório e qualitativo, este estudo tem como unidade de análise o vídeo "PAREDES-PINTURAS em Santo André". Quanto ao método de análise se dará pela análise do conteúdo tendo como foco as falas dos moradores. Após análise, o estudo mostrou que o projeto PAREDES-PINTURAS propondo-se como um espaço de expressão artístico-cultural, provocou não somente a mudança estética das casas e do bairro, mas promoveu a transformação interna do indivíduo - ser humano e cidadão.

Palavras-chave: cotidiano; percepções; sentidos; casas; arte.

\section{Resumen}

Visto en el contexto de la vida cotidiana, el objetivo de este estudio es comprender las nuevas percepciones y nuevos significados construidos por los residentes para ver sus casas pintadas, después de la intervención de la pared del proyecto pinturas. Exploratorio y cualitativo, este estudio tiene la unidad de análisis del video "las pinturas murales de San Andrés." El método de análisis se llevará a cabo el análisis de contenido centrándose en las líneas de los residentes. Tras el análisis, el estudio mostró que el proyecto de pinturas de la pared se presenta como un espacio para la expresión artística y cultural, provocada no sólo cambiar la estética de los hogares y el barrio, sino que promovió la transformación interna del individuo - humanos y el ciudadano.

Palabras clave: la vida cotidiana; las percepciones; los sentidos; las habitaciones; arte.

\section{Abstract}

Seen in the context of everyday life, the purpose of this study is to understand the new perceptions and new meanings constructed by the residents to see their houses painted, after the intervention of the project wall-paintings. Exploratory and qualitative, this study has the unit of analysis the video "wall-paintings in St. Andrew." The method of analysis will be done by content analysis focusing on the lines of the residents. After analysis, the study showed that the project wall-paintings present itself as a space for artistic and cultural expression, caused not only change the aesthetics of homes and the neighborhood, but promoted the internal transformation of the individual - human and citizen.

Keywords: daily life; perceptions; senses; homes; art. 


\section{A HUMANIZAÇÃO DA CASA E DO INDIVÍDUO: PROJETO PAREDES-PINTURAS}

\section{Introdução}

Toda ação humana se dá no espaço da vida cotidiana. É no contexto da vida cotidiana e nas relações interpessoais dos grupos que as subjetividades, as emoções, os comportamentos e as representações são constituídos. É neste mesmo espaço que o ser social se constitui, produz-se e se reproduz.

Neste contexto, apresenta-se o Projeto PAREDES PINTURAS, que visa se constituir como uma alternativa artística e cultural ao abrir um conjunto de possibilidades de envolver a comunidade da periferia em uma ação positiva, resgatando-lhes o direito à cidadania e fazendo com que a manifestação artística possa ser compartilhada, desenvolvida e motivo de pleno envolvimento social.

Este é um Projeto que concilia arte contemporânea e ação social, ao procurar incitar nos moradores do município de Santo André, a vontade de criar desenhos e motivos decorativos a partir de seus repertórios culturais, reconstruindo o espaço da casa e do bairro, promovendo a renovação de seus espaços individuais e comunitários. Assim, a proposta deste estudo é compreender as percepções e as ressignificações construídas pelos receptores (moradores) ao verem suas casas pintadas. O intuito é apresentar uma perspectiva subjetiva do indivíduo não apenas como um elemento da cadeia produtiva, mas um ser humano e cidadão - sujeito histórico.

De caráter qualitativo e exploratório, este estudo tem como unidade de análise o projeto apresentado focando na população receptora, moradores do bairro Jardim Santo André (SP). Para tal, o método de análise se dará pela análise do conteúdo (Bardin, 1977) tendo como objeto o vídeo "PAREDES-PINTURAS em Santo André”.

\section{Apresentação do problema}

O Projeto PAREDES-PINTURAS ocorre há 10 anos em bairros periféricos do Brasil e da América Latina e consiste em realizar pinturas murais em escolas e casas, praças e muros do bairro, ou seja, locais fora dos circuitos artísticos convencionais, modificando não apenas a parte física e estética do espaço urbano, mas contribuindo para abrir caminhos de transformação na própria vida dos atores envolvidos.

O contexto em que o Projeto se insere é caracterizado pela proliferação de moradias em bairros periféricos da cidade, fruto do processo de urbanização caótico acompanhado do crescimento desenfreado das cidades e da presença da especulação imobiliária nos grandes centros.

A região de atuação do Projeto em estudo é caracterizada pela falta de sane- 


\section{A HUMANIZAÇÃO DA CASA E DO INDIVÍDUO: PROJETO PAREDES-PINTURAS}

amento básico e infra-estruturada adequados, pela carência de equipamentos educacionais e culturais e disponibilidade de espaços para prática de esportes e lazer. Soma-se ainda a escassez de alternativas e oportunidade de geração de renda e de trabalho, entre outros aspectos. Enfim, este breve cenário retrata a precariedade das condições de vida dos moradores do bairro Jardim Santo André, que diante das baixas perspectivas de vida e oportunidades vêem reduzidas suas possibilidades de crescimento pessoal e profissional.

Nota-se que o Projeto PAREDES-PINTURAS representa um espaço privilegiado de comunicação e expressão da arte e cultura da comunidade da periferia do Jardim Santo André (SP) por trabalhar com questões como afirmação de identidades culturais, memória coletiva, reconstrução da cidadania e humanização do sujeito no espaço do cotidiano.

Assim, ao considerar que a atuação do Projeto interfere na reconstrução física e estética do espaço urbano e, por conseguinte, potencializa a transformação individual e coletiva, este estudo tem como objetivo geral compreender as percepções e as ressignificações construídas pelos receptores (moradores) após a intervenção sóciocultural no espaço em que vivem.

Como objetivos específicos: ampliar o conhecimento e a produção científica em cultura e comunicação, estabelecer a ponte dos estudos de Comunicação e Cultura no contexto das interfaces sociais e contribuir para os estudos e práticas de projetos de intervenções sociais tendo como foco os indivíduos receptores da ação social.

\section{Marcos teóricos e conceituais - Conceito de Cotidiano}

Como concepção totalizante da vida cotidiana, como centro de sistema de comunicação e informação entre indivíduos, a cotidianidade é o cenário privilegiado onde podem se encontrar as possibilidades transformadoras da sociedade.

A vida cotidiana pode ser entendida como o lugar da realização do homem, ou seja, o local onde é possível compreender o processo social e cultural em toda a sua totalidade. Ferreira (2007) coloca que o cotidiano é o lugar onde as práticas concretas dos homens com a natureza, com os deuses e com os outros homens se traduzem em experiências sociais.

Outros estudiosos como Netto e Falcão (1988), ao tratarem do conceito de cotidiano abordam que a cotidianidade contém alguns aspectos fundamentais para a constituição cultural. São eles o cenário das experiências materiais e concretas e também de construção da subjetividade, das emoções, comportamentos e representações. (NETTO; FALCÃO, 1988: 45) 


\section{A HUMANIZAÇÃO DA CASA E DO INDIVÍDUO: PROJETO PAREDES-PINTURAS}

É, pois, neste espaço privilegiado que será importante estudar este processo cultural dos moradores do bairro Jardim Santo André, população foco deste estudo.

\section{O cotidiano na estética de Lukács}

A estética de Lukács (1974) tem como uma de suas peculiaridades o fato de buscar um enraizamento na vida cotidiana. Para Lukács (1974), o comportamento cotidiano do homem, assim, é o começo e o fim de toda ação humana. O mesmo autor afirma que a vida cotidiana é insuprimível, que não há sociedade sem cotidianidade, não há homens sem vida cotidiana. É no espaço-tempo da vida cotidiana que o ser social se constitui, produz-se e se reproduz.

Na heterogeneidade própria à vida cotidiana, o indivíduo age como um homem inteiro, mas sempre no âmbito da singularidade. Ao superar a singularidade, situação em que o indivíduo deposita todas as suas forças numa objetivação duradoura, suspendendo a heterogeneidade da vida cotidiana. Nessa suspensão da heterogeneidade da cotidianidade, o indivíduo se instaura como particularidade, espaço de mediação entre o singular e o universal, e comporta-se como inteiramente homem.

De acordo com Lukács (1974), o trabalho criador, a arte e a ciência são procedimentos homogeneizadores que superam a cotidianidade. Frederico (2000) assinala que

\footnotetext{
"Na visão ontológica de Lukács, a arte é uma atividade que parte da vida cotidiana para, em seguida, a ela retornar, produzindo esse movimento reiterativo uma elevação na consciência sensível dos homens." (FREDERICO, 2000: 04)
}

O retorno à cotidianidade após uma suspensão (criativa, fruidora) contribui para a construção de um indivíduo mais refinado, educado, pois o sujeito que a ela regressa está modificado.

Conforme Frederico (2000):

"A arte, portanto, educa o homem fazendo-o transcender à fragmentação produzida pelo feti-
chismo da sociedade mercantil. Nascida para refletir sobre a vida cotidiana dos homens, a arte
produz uma "elevação" que a separa inicialmente do cotidiano para, no final, fazer a operação de
retorno. Esse processo de circular produz um contínuo enriquecimento espiritual da humanida-
de." (FREDERICO, 2000: 04)

Assim, a cotidianidade é concebida como espaço compulsório de humanização e de enriquecimento e ampliação do ser social. 


\section{A HUMANIZAÇÃO DA CASA E DO INDIVÍDUO: PROJETO PAREDES-PINTURAS}

\section{O valor simbólico da casa}

Observa-se que em virtude do contexto de subcidadania (KOWARICK, 2000) em que as garantias e direitos são suprimidos, sobressaem os anseios pela realização de projetos individuais (privado) em detrimento dos projetos coletivos (público).

Para efeito deste estudo, o projeto individual colocado por Kowarick (2000), centra-se no espaço da moradia, da casa. O mesmo autor acrescenta que a moradia é o primeiro núcleo social do indivíduo, é o espaço onde se processa a organização do espaço familiar, onde são fomentados, criados, executados ou frustrados múltiplos projetos, carregados de conseqüências materiais e plenos de significação simbólicos.

A casa própria apresenta uma conotação positiva, símbolo de vitória, constitui refúgio de características eminentementes defensivas em metrópoles do subdesenvolvimento industrial, cuja característica básica é fazer do espaço público em espaço excludente e violento. Assim, o ambiente da casa apresenta-se como um espaço pleno de significados materiais e simbólicos.

O valor simbólico atribuído à casa, em especial, à casa própria apresenta-se como sinônimo de sucesso e isto se estende aos indivíduos, aos moradores da casa. No mesmo sentido, o valor pejorativo atribuído à favela e/ou ao cortiço, estigmatizados como espaços de violência, imoralidade e promiscuidade, também são valores estendidos aos moradores desses ambientes. Assim, pode se perceber a associação direta estabelecida entre o tipo de moradia e os indivíduos que a habitam e vice-versa.

Um estudo realizado por Tavares e Albertini (2005) reforça essa idéia ao investigar a relação intrincada e intensa entre formas de subjetividade e de moradia, mediada pela corporeidade, no contexto limiar da favela.

Conforme o estudo,

\footnotetext{
"Quando se encontram casas e corpos habitados, pode-se falar de casas que são corpos habitados e de corpos que também são casas, o que só ocorre quando eles se assentam em redes de sociabilidade, a base para reafirmar a noção de desenvolvimento humano enquanto apropriação da cultura e forma de resistência." (TAVARES; ALBERTINI, 2005: 307)
}

No mesmo estudo, Tavares e Albertini (2005) constatam que na favela se revelam as mais diversas e intrigantes formas de corpos e de casas, construídos na tentativa de humanizar o espaço.

Assim, coloca-se:

"A casa, para ser abrigo e compor uma comunidade de destino, precisa ser a encarnação do 


\section{A HUMANIZAÇÃO DA CASA E DO INDIVÍDUO: PROJETO PAREDES-PINTURAS}

destino afetivo de uma comunidade e de cada sujeito que nela habita. Sem essa costura intersubjetiva, corpos e casas desabam, desmancham no ar." (TAVARES; ALBERTINI, 2005: 307)

Ao retomar Kowarick (2000) que atribui à casa a encarnação da realização de um projeto individual de existência, no contexto da subcidadania, a casa também representa o núcleo da sociabilidade baseada em contatos primários. Enfim, pode-se dizer que a casa representa o microcosmo, o espaço para organização do caos presente na realidade, no macrocosmo.

\section{Metodologia, procedimentos e estratégicas metodológicas}

Para o desenvolvimento do presente estudo considera-se necessária a adoção da perspectiva da "filosofia da práxis" gramsciana (Semeraro: 2000), isto é, ter como ponto de partida a realidade concreta pensada teoricamente para sua confrontação com o objeto construído. Isto compreende que a perspectiva metodológica é a construção de uma relação dialética entre sujeito e objeto de pesquisa tendo como mediação o referencial teórico.

O presente estudo trata-se de uma pesquisa exploratória de caráter qualitativo que foi fundamentada por pesquisa bibliográfica e análise documental do vídeo "Projeto PAREDES-PINTURAS em Santo André”.

Com o intuito de compreender quais são as novas percepeções e novos sentidos criados pelos moradores após verem suas casa modificadas, o referencial teórico centrou-se no conceito de cotidiano (NETO; FALCÃO, 1988), o conceito e o papel da arte proposto por Lukács (1974) como instrumento humanizador no contexto do cotidiano e o valor simbólico da casa apresentado por Kowarick (2000), Tavares e Albertini (2005).

Ao considerar o objetivo deste estudo, o método utilizado no processo de análise foi a análise de conteúdo (BARDIN, 1977). Vale mencionar que o estudo considerou as falas dos moradores presentes no vídeo "Projeto PAREDES-PINTURAS em Santo André”.

Bardin (1977) conceitua a análise de conteúdo como sendo:

\footnotetext{
"um conjunto de técnicas de análise das comunicações visando, por procedimentos sistemáticos e objetivos de descrição do conteúdo das mensagens, obterem indicadores, quantitativos ou não, que permitam a inferência de conhecimentos relativos às condições de produção e recepção das mensagens. Caracteriza-se pela sua capacidade de obter a análise de significados." (BARDIN, 1977: 42)
}

Por fim, ressalta-se que o presente estudo foca nos moradores, receptores do 


\section{A HUMANIZAÇÃO DA CASA E DO INDIVÍDUO: PROJETO PAREDES-PINTURAS}

Projeto, entendendo que a interação do sujeito (o morador) e o objeto (a casa) sofrem influencias e transformações mútuas, sendo este um processo dialético e que geram novas percepções e novos sentidos para os atores envolvidos.

\section{Apresentação e interpretação dos dados coletados e obtidos}

Ao analisar o vídeo "PAREDES-PINTURAS em Santo André" verificouse que do total de 20 moradores que foram entrevistados, apenas 3 são do gênero masculino, sendo a maioria (17) do gênero feminino. Observa-se que houve a participação de uma criança com idade de 5 anos. Nota-se a expressiva participação de mulheres, fato que influenciará na análise dos resultados devido à diferença de relação estabelecida com a casa. Neste caso, observa-se a forte presença feminina em movimentos sociais em prol da melhora na qualidade de vida própria e dos demais moradores, fato verificado nos estudos de Tavares e Albertini (2005).

Conforme a metodologia de pesquisa apresentada, o método de análise utilizada consistiu em fazer a análise do conteúdo (BARDIN, 1977) das falas dos moradores do Jardim Santo André no vídeo "Projeto PAREDES-PINTURAS em Santo André".

Após a análise dos resultados, para efeito de estudo, foi feita uma divisão dos resultados obtidos em 3 categorias, sendo as seguintes:

1. Relação Indivíduo - Indivíduo

2. Relação Indivíduo - Casa

3. Relação Indivíduo - Comunidade

A primeira categoria "a" englobou as percepções na dimensão intrapessoal, da relação indivíduo consigo próprio. Os principais aspectos apontados pelos moradores entrevistados foram: sentimento de orgulho próprio, capacidade de realização e transformação, valorização da auto-estima e valorização das relações de amor, carinho e afetividade consigo e com o próximo.

Nota-se que os aspectos relacionados reforçam o sentido de sujeito, pois trabalha o senso de identidade e singularidade dos participantes, pois ao terem um espaço em que podem expressar o que gostam, o que sentem, refletem nos desenhos e pinturas o seu repertório cultural e a memória individual e coletiva. Na Relação Indivíduo - Indivíduo, os moradores entrevistados criam novas percepções de si mesmos, como seres capazes de realizar e transformar espaço em que vivem, como sujeitos que têm gostos, anseios, necessidades e carências para serem supridas. Ressalta-se ainda outro aspecto positivo intra e inter pessoal percebido pelas falas dos moradores, foi o fato de despertar e/ou estimular gestos e ações de carinho e afeto por si e por seus 


\section{A HUMANIZAÇÃO DA CASA E DO INDIVÍDUO: PROJETO PAREDES-PINTURAS}

entes próximos.

A segunda categoria " $b$ " buscou analisar a relação do indivíduo com a casa, sendo os principais aspectos levantados: sentimento de posse e orgulho da casa, associação da casa à proteção, ao conforto e à segurança, valorização da casa e do lugar onde mora e melhora da qualidade de vida.

Ao analisar as falas dos moradores, percebe-se uma relação de afeto pela casa, esta vista como espaço físico de conforto e proteção, que reflete o próprio morador. $\mathrm{O}$ olhar para casa humana seria ao mesmo tempo vislumbrar a história - pessoal e coletiva de sujeitos - e perceber a existência de diferentes formas de subjetividade, ou de habitação, no cotidiano e no lar.

Assim, reconstruir a própria casa implica ressignificar o próprio indivíduo, o sujeito. Retomando os estudos de Tavares e Albertini (2005), que tratam da relação da casa bem cuidada corresponde ao morador com a auto-estima valorizada, ou seja, o quanto a humanização da casa reflete na própria humanização do indivíduo, e viceversa. Percebe-se pela análise e conforme apontado pela teoria, a casa apresenta-se como um espaço pleno de significados materiais e simbólicos, campo propício para exploração e estudo da relação "casas habitadas - corpos habitados", conforme proposta de Tavares e Albertini (2005).

A terceira categoria "c" deste estudo versa sobre a relação do indivíduo com a comunidade e os principais aspectos apresentados foram: novas percepções e ressignificações do indivíduo, da casa e da comunidade e quebra do estigma de favela. Ao estabelecer esses novos vínculos do indivíduo com a casa, espaço que contém e representa a sua existência, a sua história e a sua identidade cultural, nota-se que houve o rompimento com a heterogeneidade do cotidiano, como colocado por Lukács (1974), o que propicia uma nova percepção de si e do entorno e novas ressignificações.

Isto redimensiona os sentidos e os símbolos que estes indivíduos possuem em relação aos seus espaços de convivência individual e coletiva. Embora os estigmas de favela estejam associados a termos pejorativos, esse processo de reconstrução do espaço físico urbano da casa influenciou no processo de novas percepções do entorno, em que a favela se transforma em comunidade, como demonstrado pela fala de uma das moradoras entrevistadas:

\footnotetext{
“(...) incentiva, anima a gente a continuar... tudo pintadinho, bonitinho, cada um com a sua idéia, cada casa de uma cor, vai fica "dá hora", não vai ser mais uma favela como dizem, vai ser uma comunidade." (Moradora 18 - vide em "Apêndice")
}

Ao compreender e desvendar a realidade na sua concretude, o indivíduo toma consciência de seu lugar enquanto sujeito da história e poderá tecer outras realidades 


\section{A HUMANIZAÇÃO DA CASA E DO INDIVÍDUO: PROJETO PAREDES-PINTURAS}

mais humanizadoras. Assim, o espaço de humanização do indivíduo é possibilitada na prática cotidiana, conforme apontado pela teoria. Nota-se pela análise, a interação das três categorias apresentadas como forma de elucidar e compreender as percepções e as ressignificações criadas pelos moradores após a atuação do projeto PAREDES-PINTURAS.

Por fim, vale assinalar que no momento em que o projeto PAREDES-PINTURAS se propõe a ser um espaço de expressão artístico-cultural, explorando o repertório cultural e a memória coletiva dos moradores, fazendo uso da arte com desenhos e pinturas, objetiva-se não somente a mudança estética das casas e, por conseguinte, do bairro, mas provoca-se a transformação interna do indivíduo, do ser humano e cidadão. Este, ao retornar para o cotidiano, está transformado e com isso reconstrói a si mesmo e ressignifica sua realidade e seu mundo - macro e micro.

\section{Considerações finais}

Toda ação humana se dá no espaço da vida cotidiana. É no contexto da vida cotidiana e nas relações interpessoais dos grupos que as subjetividades, as emoções, os comportamentos e as representações são constituídas. É neste mesmo espaço que o ser social se constitui, produz-se e se reproduz.

A partir deste estudo foi possível constatar o importante papel da arte no processo dialético de humanização do indivíduo e humanização da casa.

O Projeto PAREDES-PINTURAS ao propiciar um espaço para produção e expressão artístico-cultural dos moradores do Jardim Santo André (SP), possibilitou, por meio da arte, conforme Lukács (1974) a suspensão da heterogeneidade da vida cotidiana.

Nesse processo de rompimento com o cotidiano, o indivíduo instaura-se como particular e comporta-se como inteiramente homem (LUKÁCS, 1974), mais refinado, educado, pois o sujeito que à realidade regressa está modificado. Esta ruptura faz com que a percepção dos indivíduos, o olhar sobre si e sobre o entorno sejam modificados, propiciando novas ressignificações e reconstruções de sentidos, abrindo novas perspectivas para transformações individuais e coletivas. 


\section{A HUMANIZAÇÃO DA CASA E DO INDIVÍDUO: PROJETO PAREDES-PINTURAS}

\section{Referências bibliográficas}

BARDIN, L. “Análise de conteúdo". Trad. de Luis Antero Reto e Augusto Pinheiro. Lisboa: Edições 70; 1977.

FERREIRA, Maria Nazareth. “Os desafios da Produção Científica no Neoliberalismo: as culturas e a comunicação subalternas" in: "Comunicação e Política", Rio de Janeiro: janeiro-abril de 2007, v. 25, $\mathrm{n}^{\circ}$ 01,

FREDERICO, C. “Cotidiano e Arte em Lukács”. Estudos Avançados, vol.14, n 40 São Paulo. set/dez 2000.

KOWARICK, Lúcio. “Escritos Urbanos”. São Paulo, Editora 34, 2000.

LUKÁCS, G. Estética, v. I, Barcelona: Ed. Grijalbo,1974, p. 11-12

NETO, J. P; FALCÃO, M. C. “Cotidianidade: Conhecimento e Crítica”. São Paulo: Cortez, 1988.

SEMERARO, G. "Anotações para uma Teoria do Conhecimento" in: "Gramsci e os novos embates da filosofia da práxis". Aparecida: Idéias \& Letras, 2000.

TAVARES, S. M. G.; ALBERTINI, P. “Moradia e corporeidade em espaços liminares: um estudo sobre formas de subjetividade na favela”. Paidéia (Ribeirão Preto): Ago 2005, vol.15, n 31, p.299-308. ISSN 0103-863X

ANEXOS E APÊNDICES (vídeo e evento artístico realizados)

Anexo 1: DVD "PAREDES - PINTURAS no Jardim santo André"

Uma Parceria: Companhia de Desenvolvimento Habitacional e Urbano - CDHU e Jardim Miriam Arte e Clube - JAMAC

Anexo 2: Exposição do Projeto PAREDES-PINTURAS no Museu da Casa Brasileira em junho de 2009 - "Pintura na Margem da Cidade". 


\section{A HUMANIZAÇÃO DA CASA E DO INDIVÍDUO: PROJETO PAREDES-PINTURAS}

\section{Apêndice}

Transcrição do vídeo "Projeto PAREDES-PINTURAS"de Mônica Nador no Jardim Santo André, desenvolvido em parceria com a CDHU - Programa São Paulo de Cara Nova

\section{Legenda de nomenclaturas}

\begin{tabular}{|l|l|l|}
\hline MN- Mônica Nador & M2- Moradora 2 & M12- Moradora 12 \\
\hline DV- Daniela Vidueiros & M3- Moradora 3 & M13- Moradora 13 \\
\hline P- Paulinho & M4- Moradora 4 & M14- Moradora 14 \\
\hline J- Juscelino & M5- Moradora 5 & M15- Moradora 15 \\
\hline JA- Jacinto & M6- Moradora 6 & M16- Moradora 16 \\
\hline VI- Viviane da CDHU & M7- Moradora 7 & M17- Moradora 17 \\
\hline CR1- Criança 1 & M8- Moradora 8 & M18- Moradora 18 \\
\hline ME1- Menina 1 & M9- Moradora 9 & M19- Moradora 19 \\
\hline ME2- Menino 2 & M10-Moradora 10 & M20- Moradora 20 \\
\hline M1- Moradora 1 & M11- Moradora 11 & \\
\hline
\end{tabular}

MN: ... agora a CDHU vai rebocar a casa pra gente e pintar... e a gente só vai fazer nosso trabalho de arte. Então, isso vai acontecer numa rua aqui... serão 26 casas... e assim, a gente vai completar o piloto.

DV: ... e nós estamos aqui em Santo André pra desenvolver esse projeto que se chama "Arte em toda parte" que é pra trazer um pouco de cor pro bairro, um pouco de alegria com os desenhos da comunidade pra que eles se identifiquem com aquele trabalho

P: ... é um trabalho coletivo assim... de pegar a experiência de cada um e transformar num resultado final.

M1: ... porque pode ser estampado em camisetas, roupa, no muro. Então muda NE, torna-se uma coisa diferente, NE.

JA: Em todos os lugares a arte tem uma importância enorme.

DV: A arte é uma forma gostosa de se aprender, né.

JA: ... e a gente ensina isso aqui, das pessoas se expressarem com desenho. 


\section{A HUMANIZAÇÃO DA CASA E DO INDIVÍDUO: PROJETO PAREDES-PINTURAS}

Então elas fazem o desenho e a gente ensina a passar isso pro extênsil, a cortar...

MN: vai começar agora a capacitar os meninos daqui. Então, eu sempre os desenhos que sejam referenciados na realidade concreta das pessoas que estão participando... é... um pouco contra a realidade virtual. Eu falo que eu quero a realidade concreta... coisas que eles possam pegar e ter, né. E... as coisas que eles gostem, né... coisas que eles gostem, que tenha um laço positivo com a coisa representada, né.

M2: Eu desenhei um cangaceiro, um lampião puxando um cachorro, um coqueiro, uma flor, um sol, um patinho num lago com os filhotes, uma casa com

DV: ... a gente ta treinando os garotos aqui do Jardim Santo André pra que eles possam reproduzir o trabalho sem nós. A gente está dando este treinamento pra que este trabalho continue por muito tempo.

VI: A sustentabilidade da organização passa por um desenvolvimento humano, comunitário, geração de renda, capacitação inclusive pra arte.

MN: Depois então de feitos esses desenhos... a gente passa alguns pro... é ... pro acetato né... pra fazer as máscaras e pra fazer as decorações nas casas, né.

P: É um processo rápido, de fácil aprendizado que não precisa ter muita noção de desenho.

MN: É assim, aos pouquinhos o povo vai colando... por isso precisa ficar muito tempo... tudo isso, né.

M3: Você vai ficar orgulhosa da gente... do nosso trabalho.

JA: ... se você se relaciona, você divide mais, você troca mais, você cresce mais, você aprende mais. vimento

VI: O conhecimento, o contato com novas linguagens faz parte do desenvol-

MN: É a primeira casa do nosso projeto aqui da CDHU. Então a gente ta fazendo a fruteira da Márcia e as borboletinhas da filha da Márcia, na casa da Silvana e das suas três filhas aqui no Jardim Santo André.

M4: Esta é a minha casa, né. Foi arrumado, foi pintado, deu uma nova aparência, né. Ela tá chamando a atenção. 


\section{A HUMANIZAÇÃO DA CASA E DO INDIVÍDUO: PROJETO PAREDES-PINTURAS}

VI: Da apropriação do espaço pela comunidade, do espaço onde acontece a vida.

M5: Pra um dia em que eu tivesse meus filhos e Deus me tirasse, eu deixar eles em uma casa, que foi o que meus pais não fizeram comigo. Eu fiquei na casa dos outros, né,... agüentando humilhação, então não é isso que eu quero pros meus filhos.

M6: Eu achava que eu não tinha capacidade de fazer a xícara, fazer aquele desenho todo e transformar aquele muro, porque ficou muito legal, ficou bem diferente.

JA: ... aplicam aquele trabalho na parede da sua própria casa, dentro de casa.... sem que a gente fale assim "faz assim ou assado", não ela vai lá, tem a iniciativa, vai lá e faz.

M7: Ah, eu gostei muito, ah ela falou "se quê ajuda?" e eu falei "ah eu quero!" e eu comecei a fazer, comecei e ajudei a terminar também... eu já gostava também de mexer mesmo com essas coisas manual, pra mim foi bom, foi uma experiência, aprendi um pouco também e continuo.

M5: Como lá fora ta bonito, então eu também quero que aqui dentro também fique bonito.

M7: Ah é... é... muda, né, fica diferente, dá mais valor pro lugar.

M8: Porque é o lugar aonde a gente mora, né, tem que ser bonito...

M9: ... é que se eu soubesse que ia acontecer com um monte de casa aí, porque dá um visual bem melhor pro nosso bairro.

M8: ... achei diferente né, porque não é todas que você vê assim... porque por aí eu só vi aqui assim.

M1: Eu desenhei uma árvore com florzinhas, uma borboleta porque minha mãe adora borboleta, então eu coloquei ela.

M1: (mãe) Porque borboleta é mudanças... transformação

(menina) ... ah é muitolegal, é divertido, você se distrai bastante... eu to aprendendo coisas novas.

(mãe) ... que ela vão criar alguma coisa, que elas estão criando uma coisa que elas realmente pensam.

CR1: ... eu queria que fazer um parquinho lá, mas que com balança, que podia andar de bike, que podia fazer ginástica, correr... 


\section{A HUMANIZAÇÃO DA CASA E DO INDIVÍDUO: PROJETO PAREDES-PINTURAS}

Cena de duas meninas brincando de palmas.

M10: É que nem eu falei pra elas. Eu queria uma coisa assim... não extravagante mas uma coisa simples, mas que fosse uma coisa que pudesse apresentar, né?! Ficar bem bonitinho lá na frente.

DV: ... e a casa da Eunice a gente vai fazer uma florestona de coqueiro lá na parede da frente... ela gostou da idéia.. e agente vai viajar nela.

M11: ... ta assim... mudou algumas coisas... é ... ta ficando mais lindo, né?! "perfeiçoando" a casa né. É porque a gente fica mais alegre vendo as coisas ficando bonito assim, feliz, né.

M12: ah, escolhemos um desenho pra ficar do lado de fora, pintar... tem uns pé de orquídea, e aqui pro lado de dentro, vai pintar de cor de laranja.

ME1: Ainda tem muita coisa pra fazer, mas quem sabe melhora até nossa auto-estima. Dá vontade... de ânimo de querer... pelo menos querer terminar, né.

M13: vai ficar "binito".

MN: ... a gente ta indo pro nosso barracão... nosso "ateliezão"... vamos cortar a máscara do Daniel... pra gente começar a fazer a parede do Daniel.

M14: ... todo mundo fazer isso, uma coisa bem bonita igual o que a gente ta fazendo... eu acho que aqui é uma favela mas eu acharia que melhoraria mas.

M15: ... a casa feia ninguém quê né.

ME2: ... porque a casa bonita "nóis" dá valor... a casa feia "nóis" nem liga, né?!

M16: (Menina) o que eu mais gostei é que eles reformaram minha casa por fora, e agora dentro como temmreboco, a gente não passa muito frio nos tempos de frio, sei lá.

(mãe)... mas o que mais me chamou a atenção.. mas o mais legal mesmo foi os desenhos da porta... bem achei mesmo bem bonito mesmo foi as florzinhas que vocês fizeram na porta... eu achei que deu um destaque bom. também.

(menina) Gostei da pintura... das coisas que foram colocadas e os desenhos

(menino)... o que fizeram? ... pinto, reboco, fez flores, fez desenhos, tudo, ficou bonito. 


\section{A HUMANIZAÇÃO DA CASA E DO INDIVÍDUO: PROJETO PAREDES-PINTURAS}

(mãe)... dá mais aparência... ampara mais no frio, dos insetos, então fica tudo mais... mais... a gente se sente mais protegido.

(menina)... ah, diz que minha casa tá parecendo casa de boneca.

M17: ... mas eu acho que fica bonito... o verde é bonito e o amarelo também é. Ah, eu quero que faz um destaquizinho só assim, entre as duas cores, né?!... um destaquizinho, coisa pouca né?! Não gosto de coisa muito florida, não. Ah, uma coisinha mais simples eu acho mais elegante, na?! Uma vistazinha melhor, né, fica mais alegre.

M18: Agora vai pintar de laranja, embaixo vai pintar de cinza grafite. Dentro eu vou colocar o coqueiro, vou desenhar umas formiguinhas subindo e descendo as portas e janelas... da mesma cor debaixo.... aí dá um incentivo pra gente pintar por dentro, cuidar da casa por dentro, né. Agora a casa do jeito que ficava, a agente não tinha nem ânimo né?! ... incentiva, anima a gente a continuar... tudo pintadinho, bonitinho, cada um com a sua idéia, cada casa de uma cor, vai fica "dá hora", não vai ser mais uma favela como dizem, vai ser uma comunidade.

VI: ... é a criação de uma nova identidade. Que cara tem um bairro que passa por um processo de recuperação, de intervenção urbana? Que cara ele vai ficar? Como é que ele perde o estigma de favela? Quando ele deixa de ser uma favela?

M19: (mulher)... assim, a gente tava pensando em desenhar um cachorrinho que nem ta feito ali... sente mais bem, mais aliviado... não tem vergonha... ah, aqui é a minha casa... mal pintada assim... põe pra ela ficar mais bonitinha, pintadinha, do jeito que a gente escolheu, do jeito que a gente quer... achei muito interessante. $\mathrm{Ah}$, eu achei muito importante quando ela falou assim "você desenha que a gente vai colocar na sua casa". Nossa vai ser um desenho meu no muro? Todo mundo vai passar, olhar. Assim eu fiquei muito feliz em ter visto o meu desenho todo dia ali... é a minha criatividade.

(marido) ... porque melhora a qualidade de vida não só minha, mas de todos os moradores da rua.

M20: Não é legal você chegar... você chegar numa casa... não é gostoso você chegar numa casa ... tudo limpinho, arrumadinho... pintada, com piso, quem não... acho até que quem já tem uma casa, que já nasceu numa casa linda, como se diz?... berço de ouro, talvez não vai dar valor, mas quem não tem, quer. Eu nunca tive, então eu quero. É meu sonho ter minha casa... minha casa bem arrumada. Ah é, já deu até uma... até a auto-estima da gente melhora, sobe. Não é?

M19: (mulher) Ah, meu irmão que teve a idéia de fazer os desenhos. A gente ficou martelando que desenho ia fazer, até que ele deu uma sugestão e a gente gos- 


\section{A HUMANIZAÇÃO DA CASA E DO INDIVÍDUO: PROJETO PAREDES-PINTURAS}

tou e colocamos este desenho aí. Tem muita gente que tem preconceito né?! Por ser favela. "Ai, vai entrar na favela?" Ai ficar um lugar meio sombrio, então vendo um colorido dá um ar mais leve, eu acho... pelo menos eu sinto assim.

M17: sabe o que que é o amor? Às vezes eu falo que eu não sei o que que é o amor. Amor, mas amor é uma coisa muito importante né?! Quando você gosta, ama aquele objeto, você não quer vê ele destruído. Porque eu amo isso aqui, porque foi o local que eu cheguei pra mim agasalhar, e graças a Deus (suspiro), achei mais um pouquinho de paz.

M18: (amiga1)... bem melhor, em vista como era uns 10 anos atrás. (amiga 2) ... tudo colorido, cada casa um jeito, ficou muito bom. (amiga 1) Muito bom.

M17: Oi, pra mim ta jóia! 